\section{Comparison of the diagnostic performance of the modified Korean Thyroid Imaging Reporting and Data System for thyroid malignancy with three international guidelines}

Eun Ju Ha', Jung Hee Shin ${ }^{2}$, Dong Gyu Na ${ }^{3}$, So Lyung Jung ${ }^{4}$, Young Hen Lee ${ }^{5}$, Wooyul Paik ${ }^{3}$, Min Ji Hong ${ }^{6}$, Yeo Koon Kim ${ }^{7}$ Chang Yoon Lee ${ }^{8}$

*Author affiliations appear at the end of this article.

Purpose: This study compared the diagnostic performance of the modified Korean Thyroid Imaging Reporting and Data System (K-TIRADS) for thyroid malignancy with three international guidelines.

Methods: From June to September $2015,5,708$ thyroid nodules $(\geq 1.0 \mathrm{~cm})$ in 5,081 consecutive patients who underwent thyroid ultrasound (US) at 26 institutions were evaluated. The US features of the thyroid nodules were retrospectively reviewed and classified according to all four guidelines. In the modified K-TIRADS, the biopsy size threshold was changed to $2.0 \mathrm{~cm}$ for

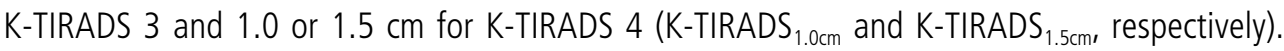
We compared the diagnostic performance and unnecessary fine-needle aspiration biopsy (FNAB) rates for thyroid malignancy between the modified K-TIRADS and three international guidelines. Results: Of the 5,708 thyroid nodules, 4,597 (80.5\%) were benign and 1,111 (19.5\%) were malignant. The overall sensitivity was highest for the modified K-TIRADS $1.0 \mathrm{~cm}(91.0 \%)$, followed by the European (EU)-TIRADS (84.6\%), American Association of Clinical Endocrinologists/American College of Endocrinology/Associazione Medici Endocrinologi (AACE/ACE/AME) (80.5\%), American College of Radiology (ACR)-TIRADS (76.1\%), and modified K-TIRADS ${ }_{1.5 \mathrm{~cm}}(76.1 \%)$. For large nodules $(>2.0 \mathrm{~cm})$, the sensitivity increased to $98.0 \%$ in both the modified K-TIRADS $1.0 \mathrm{~cm}$ and K-TIRADS ${ }_{1.5 \mathrm{~cm} .}$. For small nodules $(\leq 2.0 \mathrm{~cm})$, the unnecessary FNAB rate was lowest with the modified K-TIRADS $_{1.5 \mathrm{~cm}}(17.6 \%)$, followed by the ACR-TIRADS (18.6\%), AACE/ACE/AME (19.3\%), $\operatorname{EU}-\operatorname{TIRADS}(28.1 \%)$, and modified K-TIRADS ${ }_{1.0 \mathrm{~cm}}(31.2 \%)$.

Conclusion: The modified K-TIRADS $1.5 \mathrm{~cm}$ can reduce the unnecessary FNAB rate for small nodules $(1.0-2.0 \mathrm{~cm})$, while maintaining high sensitivity for detecting malignancies $>2.0 \mathrm{~cm}$.

Keywords: Fine-needle aspiration; Thyroid neoplasms;

Thyroid Imaging Reporting and Data System; Thyroid nodules; Ultrasonography
ULTRA

SONO

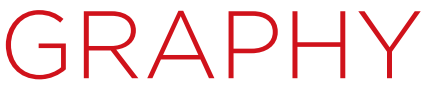

ORIGINAL ARTICLE

https://doi.org/10.14366/usg.21056 pISSN: 2288-5919 • elSSN: 2288-5943 Ultrasonography 2021;40:594-601

Received: March 92021

Revised: March 30, 2021

Accepted: April 5, 2021

Correspondence to: Jung Hee Shin, MD, Department of Radiology and Center for Imaging Science, Samsung Medical Center, Sungkyunkwan University School of Medicine, 81 Irwon-ro, Gangnam-gu, Seoul 06351, Korea

Tel. +82-2-3410-2548

Fax. +82-2-3410-0049

E-mail: jhshin11@skku.edu

This is an Open Access article distributed under the terms of the Creative Commons Attribution NonCommercial License (http://creativecommons.org/ licenses/by-nc/4.0/) which permits unrestricted noncommercial use, distribution, and reproduction in any medium, provided the original work is properly cited.

Copyright (C) 2021 Korean Society of Ultrasound in Medicine (KSUM)

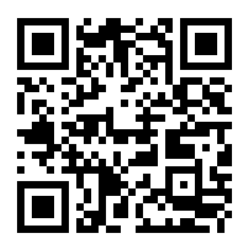

How to cite this article:

Ha EJ, Shin JH, Na DG, Jung SL, Lee YH Paik W, et al. Comparison of the diagnostic performance of the modified Korean Thyroid Imaging Reporting and Data System for thyroid malignancy with three international guidelines. Ultrasonography. 2021 Oct;40(4):594-601. 


\section{Introduction}

Ultrasonography (US) is an essential tool for assessing the risk of malignancy of thyroid nodules and deciding whether to perform fineneedle aspiration biopsy (FNAB) $[1,2]$. Therefore, many international societies have proposed US-based risk stratification systems (RSS) for the clinical management of thyroid nodules [1-5]. The Korean Thyroid Imaging Reporting and Data System (K-TIRADS) is a USbased RSS proposed by the Korean Society of Thyroid Radiology (KSThR) in 2016 [1]. Since its publication, many studies have compared the diagnostic performance of the K-TIRADS for thyroid malignancy to other RSS, and have reported its clinical usefulness [6-12]. As it allows intuitive and easy assessment of the US pattern of nodules, the K-TIRADS has been applied widely in clinical practice to classify nodules during real-time US examinations.

However, recent comparative studies of RSS reported that the USbased FNAB criteria of the K-TIRADS for nodules $\geq 1 \mathrm{~cm}$ had the highest sensitivity $(91.7 \%-100 \%)$ and lowest specificity $(15.4 \%-$ $28.7 \%)$ for thyroid cancers, and the highest unnecessary FNAB rate for benign nodules $(71.3 \%-84.6 \%)[6-9,12-15]$. The diagnostic performance was similar among the different RSS at the same biopsy size threshold for the classification categories in simulation studies $[8,15]$. The need to modify the biopsy criteria of the K-TIRADS to reduce the unnecessary FNAB rate while maintaining high sensitivity for detecting thyroid cancer has been suggested $[8,9,12,15]$.

Therefore, this study was performed to compare the diagnostic performance of the US-based FNAB criteria of the modified K-TIRADS for thyroid malignancy with the RSS of three international societies: the American College of Radiology (ACR)-TIRADS, European (EU)-TIRADS, and American Association of Clinical Endocrinologists/American College of Endocrinology/Associazione Medici Endocrinologi (AACE/ACE/AME).

\section{Materials and Methods}

\section{Compliance with Ethical Standards}

The institutional review boards of the 26 participating centers approved this study (AJIRB-MED-MDB-21-062). The requirement for informed consent was waived for this retrospective review.

\section{Study Population}

Patient data collected by 26 different hospitals in Korea (Thyroid Imaging Network of Korea registry, THINK) were analyzed. From June to September 2015, 22,775 consecutive patients underwent thyroid US at the 26 participating institutions. Among them, 16,679 were excluded due to the lack of a reference standard test (biopsy or surgery) $(n=4,304)$, thyroid nodules $<1.0 \mathrm{~cm}(n=12,130)$, or suboptimal image quality $(n=245)$. A further 1,015 patients with 1,102 nodules were excluded due to inconclusive biopsy results. A total of 5,708 thyroid nodules $(\geq 1 \mathrm{~cm})$ in 5,081 consecutive patients were finally included in this study $(4,176$ women, 905 men; mean age, 53.2 years; age range, 19 to 93 years) (Fig. 1).

Malignant nodules were diagnosed based on the histopathological results after surgery $(n=947)$ or malignant fine-needle aspiration (FNA) or core-needle biopsy (CNB) results $(n=164)$. Benign nodules were diagnosed based on the histopathological results after surgery $(n=394)$, at least two benign FNA or CNB results $(n=601)$, and one benign FNA or CNB result $(n=3,602)[16-18]$.

\section{US Examination and Image Analysis}

All US examinations were performed with a $10-12$ or $5-14 \mathrm{MHz}$ linear probe. The US images were retrospectively reviewed by 1 of 17 experienced radiologists with 8-22 years of experience in performing thyroid US using an online program (AIM AiCRO, https:// study.aim-aicro.com).

Prior to the commencement of this multicenter study, training sessions were held to establish a baseline consensus regarding the US criteria. The 17 radiologists evaluated images of 15 biopsyproven masses not included in the study, and were asked to assess the US criteria during a consensus meeting, including composition, echogenicity, margin, calcification, orientation (taller-than-wide), spongiform appearance, and intracystic echogenic foci with a comet-tail artifact. In the modified K-TIRADS, nonparallel orientation was defined as the anteroposterior diameter of a nodule being longer than its transverse diameter in the transverse plane. The benign category included spongiform or partially cystic nodules with intracystic echogenic foci with comet-tail artifact regardless of suspicious US features. All of the reviewers, who were blind to the FNAB results and final diagnoses, then assessed the US features of the thyroid nodules [3-5]. However, extrathyroidal extension status was not evaluated in this study due to a lack of standardized US criteria. An isolated macrocalcification was defined as an entirely calcified nodule with posterior acoustic shadowing, in which no soft tissue component was identified due to dark shadows on the US image [19-21]. Such nodules were classified as "intermediate suspicion" based on the modified K-TIRADS, "moderate suspicion" (4 points) based on the ACR-TIRADS, and "unclassified" based on the other RSS $[1,3-5]$.

\section{Biopsy Size Thresholds for the Modified K-TIRADS and Other RSS}

The size threshold for biopsy was increased from $1.5 \mathrm{~cm}$ to $2.0 \mathrm{~cm}$ for low-suspicion (K-TIRADS 3) nodules in the modified K-TIRADS. The size threshold for biopsy was subdivided into 1.0 and $1.5 \mathrm{~cm}$ 
22,775 Patients thyroid US



Fig. 1. Flowchart showing the study population. US, ultrasonography; FNA, fineneedle aspiration; CNB, coreneedle biopsy.

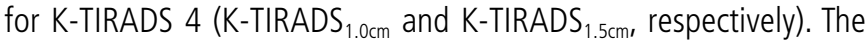
biopsy size thresholds in the RSS are shown in the Supplementary Table 1. Nodules classified as low-risk based on the AACE/ACE/AME guidelines, not suspicious (TR2) or benign (TR1) based on the ACRTIRADS, or benign based on the EU-TIRADS and modified K-TIRADS were not indicated for biopsy in this study.

\section{Statistical Analysis}

The nodules were classified according to the categories defined by the different RSS, by one radiologist (D.G.N.) with 22 years of experience in performing thyroid US and interventional procedures (Supplementary Table 1). The malignancy risk for each RSS category was calculated as a percentage. The associations between all categories and the final diagnoses were evaluated using the linearby-linear association test.

Thyroid nodules were classified into two groups: nodules in which US-guided FNAB was not indicated and nodules in which US-guided FNAB was indicated based on the criteria of each RSS (i.e., US features and nodule size). The performance of the US-based FNAB criteria of each RSS for diagnosing thyroid cancer was evaluated based on the sensitivity, specificity, positive predictive value, negative predictive value, and accuracy, and compared using the generalized estimating equation (GEE) method.

The potentially unnecessary FNAB rate was calculated according to the number of benign nodules among FNAB-required nodules in the total of thyroid nodules, and the number of benign nodules among FNAB-required nodules in the total of benign thyroid nodules. These values were calculated as percentages, and the results were compared among the guidelines using the GEE method. Statistical analyses were performed using SPSS for Windows version 23.0) (IBM Corp., Armonk, NY, USA) and SAS for Windows version 9.2
(SAS Institute Inc., Cary, NC, USA). In all analyses, $\mathrm{P}<0.05$ was taken to indicate statistical significance.

\section{Results}

Of the 5,708 thyroid nodules, 4,597 (80.5\%) were diagnosed as benign and 1,111 (19.5\%) as malignant. The 1,111 malignant nodules included 1,011 papillary thyroid carcinomas (91.0\%) and 62 follicular carcinomas (5.6\%). The mean size of the nodules was $20.7 \pm 10.8 \mathrm{~mm}$ (range, 10 to $100 \mathrm{~mm}$ ). There were 3,576 (62.6\%) small nodules $(1-2 \mathrm{~cm})$ and 2,132 (37.4\%) large $(>2 \mathrm{~cm})$ nodules. The malignancy rate was significantly higher in small tumors (1-2 $\mathrm{cm})$ than in large tumors $(>2 \mathrm{~cm})(22.7 \%[810 / 3,576]$ vs. $14.1 \%$ [301/2,132], respectively; $\mathrm{P}<0.001)$.

\section{Malignancy Risk by Category in the Different RSS}

Table 1 lists the malignancy risk for each category in the different RSS. The malignancy probability was higher in the higher risk categories of all guidelines ( $P<0.001)$. Overall, $1.0 \%(59$ of 5,708$)$ of nodules were unclassified according to the AACE/ACE/AME and EU-TIRADS; however, 33.9\% (20 of 59) of those were actually malignant.

\section{Diagnostic Performance of the Modified K-TIRADS and Other RSS}

Table 2 shows the diagnostic performance of the different RSS for thyroid cancer. The sensitivity and negative predictive value were highest for the modified K-TIRADS ${ }_{1.0 \mathrm{~cm}}(91.0 \%$ and $94.8 \%$, respectively), followed by the EU-TIRADS (84.6\% and $91.4 \%$, respectively), AACE/ACE/AME (80.5\% and $91.1 \%$, respectively), ACR-TIRADS (76.1\% and $91.4 \%$, respectively), and $K-$ TIRADS $_{1.5 \mathrm{~cm}}$ 
Table 1. Frequency and malignancy risk of tumors according to the different guidelines

\begin{tabular}{|c|c|c|c|c|c|c|}
\hline Guideline & $\begin{array}{c}\text { Benign nodules } \\
(n=4,597)\end{array}$ & $\begin{array}{l}\text { Malignant nodules } \\
(n=1,111)\end{array}$ & $\begin{array}{c}\text { Total, } n(\%) \\
(n=5,708)\end{array}$ & $\begin{array}{l}\text { Estimated risk of } \\
\text { malignancy (\%) }\end{array}$ & $\begin{array}{c}\text { Actual rate of } \\
\text { malignancy (\%) }\end{array}$ & P-value \\
\hline ACR-TIRADS 2017 & & & & & & $<0.001$ \\
\hline Highly suspicious & 388 & 609 & $997(17.5)$ & $>20$ & 61.1 & \\
\hline Moderately suspicious & 1,433 & 350 & $1,783(31.2)$ & $5-20$ & 19.6 & \\
\hline Mildly suspicious & 1,756 & 114 & $1,870(32.8)$ & 5 & 6.1 & \\
\hline Not suspicious & 795 & 31 & $826(14.5)$ & $<2$ & 3.8 & \\
\hline Benign & 225 & 7 & $232(4.1)$ & $<2$ & 3.0 & \\
\hline AACE/ACE/AME 2015 & & & & & & $<0.001$ \\
\hline High-risk & 850 & 735 & $1,585(27.8)$ & $50-90$ & 46.4 & \\
\hline Intermediate-risk & 3,439 & 349 & $3,788(66.4)$ & $5-15$ & 9.2 & \\
\hline Low-risk & 269 & 7 & $276(4.8)$ & 1 & 2.5 & \\
\hline Unclassified & 39 & 20 & $59(1.0)$ & - & 33.9 & \\
\hline EU-TIRADS 2017 & & & & & & $<0.001$ \\
\hline High-risk & 858 & 736 & $1,594(27.9)$ & $26-87$ & 46.2 & \\
\hline Intermediate-risk & 1,335 & 231 & $1,466(25.7)$ & $6-27$ & 14.8 & \\
\hline Low-risk & 2,279 & 122 & $2,401(42.1)$ & $2-4$ & 5.1 & \\
\hline Benign & 86 & 2 & $88(1.5)$ & 0 & 2.3 & \\
\hline Unclassified & 39 & 20 & $59(1.0)$ & - & 33.9 & \\
\hline Modified K-TIRADS & & & & & & $<0.001$ \\
\hline High suspicion & 244 & 536 & $780(13.7)$ & $>60$ & 68.7 & \\
\hline Intermediate suspicion & 1,180 & 362 & $1,542(27.0)$ & $15-50$ & 23.5 & \\
\hline Low suspicion & 2,864 & 204 & $3,068(53.7)$ & $3-15$ & 6.6 & \\
\hline Benign & 309 & 9 & $318(5.6)$ & $<3$ & 2.8 & \\
\hline
\end{tabular}

(76.1\% and $89.7 \%$, respectively).

The modified K-TIRADS $1.0 \mathrm{~cm}$ had significantly higher diagnostic sensitivity than the AACE/ACE/AME, ACR-TIRADS, and EU-TIRADS (all $P<0.001$ ), while it showed lower specificity than the AACE/ ACE/AME and ACR-TIRADS (both $P<0.001$ ) and similar specificity to the EU-TIRADS ( $P=0.492$ ). The modified K-TIRADS ${ }_{1.5 \mathrm{~cm}}$ had lower diagnostic sensitivity than the AACE/ACE/AME and EU-TIRADS (both $\mathrm{P}<0.001$ ), and comparable sensitivity to the ACR-TIRADS ( $\mathrm{P}=0.923)$. It also showed higher specificity than the AACE/ACE/AME and EUTIRADS (both $\mathrm{P}<0.001$ ).

When applying the FNAB criteria to large nodules $(>2.0 \mathrm{~cm})$, the sensitivity and negative predictive values increased to $89.7 \%$ $99.7 \%$ and $96.0 \%-97.8 \%$, respectively. Both the modified K-TIRADS ${ }_{1.0 \mathrm{~cm}}$ and K-TIRADS $1.5 \mathrm{~cm}$ had high diagnostic sensitivity (98.0\%) and negative predictive values (96.6\%), respectively. The modified K-TIRADS $1.5 \mathrm{~cm}$ had higher diagnostic sensitivity but lower specificity than the ACR-TIRADS ( $98.3 \%$ and $89.7 \%$, respectively, $\mathrm{P}<0.001$; and $9.4 \%$ and $40.4 \%$, respectively, $\mathrm{P}<0.001$ ).

\section{Unnecessary FNAB Rates for the Modified K-TIRADS and Other RSS}

Among the RSS, the unnecessary FNAB rates for all nodules and benign nodules were lowest with the ACR-TIRADS $(30.8 \%$ and $38.2 \%$, respectively) followed by the modified K-TIRADS ${ }_{1.5 \mathrm{~cm}}$ $(40.1 \%$ and $49.8 \%$, respectively), AACE/ACE/AME $(41.5 \%$ and $51.5 \%$, respectively), modified K-TIRADS $1.0 \mathrm{~cm}(48.6 \%$ and $60.3 \%$, respectively), and EU-TIRADS (48.9\% and $60.7 \%$, respectively) (Table 3). The modified K-TIRADS $1.5 \mathrm{~cm}$ had significantly lower unnecessary FNAB rates for all nodules than the AACE/ACE/AME, EU-TIRADS,

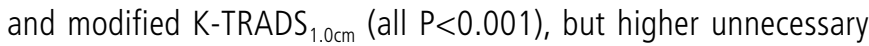
FNAB rates than the ACR-TIRADS $(P<0.001)$.

When applying the FNAB criteria to small nodules $(\leq 2.0 \mathrm{~cm})$, the unnecessary FNAB rate was lowest with the modified K-TIRADS ${ }_{1.5 \mathrm{~cm}}$ (17.6\% and $22.8 \%$, respectively), followed by the ACR-TIRADS (18.6\% and $24.0 \%$, respectively), AACE/ACE/AME $(19.3 \%$ and $24.9 \%$, respectively), EU-TIRADS ( $28.1 \%$ and $36.3 \%$, respectively), and modified K-TIRADS $1.0 \mathrm{~cm}$ (31.2\% and $40.3 \%$, respectively). The 
Table 2. Diagnostic performance of the various guidelines for detecting malignant thyroid nodules

\begin{tabular}{|c|c|c|c|c|c|}
\hline Guideline & Sensitivity (\%) & Specificity (\%) & $\begin{array}{c}\text { Positive predictive } \\
\text { value (\%) }\end{array}$ & $\begin{array}{c}\text { Negative predictive } \\
\text { value (\%) }\end{array}$ & Accuracy (\%) \\
\hline \multicolumn{6}{|l|}{ All nodules $(n=5,708)$} \\
\hline ACR-TIRADS & $\begin{array}{c}76.1(845 / 1,111) \\
{[73.5-78.5]}\end{array}$ & $\begin{array}{c}61.8(2,841 / 4,597) \\
{[60.4-63.2]}\end{array}$ & $\begin{array}{c}32.5(845 / 2,601) \\
{[30.7-34.3]}\end{array}$ & $\begin{array}{c}91.4(2,841 / 3,107) \\
{[90.4-92.4]}\end{array}$ & $\begin{array}{c}64.6(3,686 / 5,708) \\
{[63.3-65.8]}\end{array}$ \\
\hline AACE/ACE/AME & $\begin{array}{c}80.5(894 / 1,111) \\
{[78.0-82.7]}\end{array}$ & $\begin{array}{c}48.5(2,229 / 4,597) \\
{[47.0-49.9]}\end{array}$ & $\begin{array}{c}27.4(894 / 3,262) \\
{[25.9-29.0]}\end{array}$ & $\begin{array}{c}91.1(2,229 / 2,446) \\
{[89.9-92.2]}\end{array}$ & $\begin{array}{c}54.7(3,123 / 5,708) \\
\quad[53.4-56.0]\end{array}$ \\
\hline EU-TIRADS & $\begin{array}{c}84.6(940 / 1,111) \\
{[82.4-86.6]}\end{array}$ & $\begin{array}{c}39.3(1,807 / 4,597) \\
{[37.9-40.7]}\end{array}$ & $\begin{array}{c}25.2(940 / 3,730) \\
{[23.8-26.6]}\end{array}$ & $\begin{array}{c}91.4(1,807 / 1,978) \\
{[90.0-92.5]}\end{array}$ & $\begin{array}{c}48.1(2,747 / 5,708) \\
{[46.8-49.4]}\end{array}$ \\
\hline Modified K-TIRADS $1.0 \mathrm{~cm}$ & $\begin{array}{c}91.0(1,011 / 1,111) \\
{[89.2-92.5]}\end{array}$ & $\begin{array}{c}39.7(1,824 / 4,597) \\
{[38.3-41.1]}\end{array}$ & $\begin{array}{c}26.7(1,011 / 3,784) \\
{[25.3-28.2]}\end{array}$ & $\begin{array}{c}94.8(1,824 / 1,924) \\
{[93.7-95.7]}\end{array}$ & $\begin{array}{c}49.7(2,835 / 5,708) \\
{[48.4-51.0]}\end{array}$ \\
\hline Modified K-TIRADS ${ }_{1.5 \mathrm{~cm}}$ & $\begin{array}{c}76.1(846 / 1,111) \\
{[73.6-78.6]}\end{array}$ & $\begin{array}{c}50.2(2,307 / 4,597) \\
{[48.7-51.6]}\end{array}$ & $\begin{array}{c}27.0(846 / 3,136) \\
{[25.5-28.6]}\end{array}$ & $\begin{array}{c}89.7(2,307 / 2,572) \\
{[88.5-90.8]}\end{array}$ & $\begin{array}{c}55.2(3,153 / 5,708) \\
{[53.9-56.5]}\end{array}$ \\
\hline \multicolumn{6}{|l|}{ Nodules $>2.0 \mathrm{~cm}(\mathrm{n}=2,132)$} \\
\hline ACR-TIRADS & $\begin{array}{c}89.7(270 / 301) \\
{[85.7-92.7]}\end{array}$ & $\begin{array}{c}40.4(739 / 1,831) \\
{[38.1-42.6]}\end{array}$ & $\begin{array}{c}19.8(270 / 1,362) \\
{[17.8-22.0]}\end{array}$ & $\begin{array}{c}96.0(739 / 770) \\
{[94.3-97.2]}\end{array}$ & $\begin{array}{c}47.3(1,009 / 2,132) \\
\quad[45.2-49.4]\end{array}$ \\
\hline AACE/ACE/AME & $\begin{array}{c}98.3(296 / 301) \\
{[96.1-99.3]}\end{array}$ & $\begin{array}{c}8.3(152 / 1,831) \\
{[7.1-9.7]}\end{array}$ & $\begin{array}{c}15.0(296 / 1,975) \\
{[13.5-16.6]}\end{array}$ & $\begin{array}{c}96.8(152 / 157) \\
{[92.6-98.7]}\end{array}$ & $\begin{array}{c}21.0(448 / 2,132) \\
{[19.3-22.8]}\end{array}$ \\
\hline EU-TIRADS & $\begin{array}{c}99.7(300 / 301) \\
{[97.7-100.0]}\end{array}$ & $\begin{array}{c}2.5(45 / 1,831) \\
{[1.8-3.3]}\end{array}$ & $\begin{array}{c}14.4(300 / 2,086) \\
{[12.9-16.0]}\end{array}$ & $\begin{array}{l}97.8(45 / 46) \\
{[86.1-99.7]}\end{array}$ & $\begin{array}{c}16.2(345 / 2,132) \\
{[14.7-17.8]}\end{array}$ \\
\hline Modified K-TIRADS $_{1.0 \mathrm{~cm}}$ & $\begin{array}{c}98.0(295 / 301) \\
{[95.6-99.1]}\end{array}$ & $\begin{array}{c}9.4(172 / 1,831) \\
{[8.1-10.8]}\end{array}$ & $\begin{array}{c}15.1(296 / 1,969) \\
{[13.6-16.8]}\end{array}$ & $\begin{array}{c}96.6(158 / 163) \\
{[92.7-98.5]}\end{array}$ & $\begin{array}{c}21.9(467 / 2,132) \\
{[20.2-23.7]}\end{array}$ \\
\hline Modified K-TIRADS ${ }_{1.5 \mathrm{~cm}}$ & $\begin{array}{c}98.0(295 / 301) \\
{[95.6-99.1]}\end{array}$ & $\begin{array}{c}9.4(172 / 1,831) \\
{[8.1-10.8]}\end{array}$ & $\begin{array}{c}15.1(295 / 1,954) \\
{[13.6-16.8]}\end{array}$ & $\begin{array}{c}96.6(172 / 178) \\
{[92.7-98.5]}\end{array}$ & $\begin{array}{c}21.9(467 / 2,132) \\
{[20.2-23.7]}\end{array}$ \\
\hline \multicolumn{6}{|l|}{ Nodules $\leq 2.0 \mathrm{~cm}(\mathrm{n}=3,576)$} \\
\hline ACR-TIRADS & $\begin{array}{c}71.0(575 / 810) \\
{[67.8-74.0]}\end{array}$ & $\begin{array}{c}76.0(2,102 / 2,766) \\
{[74.4-77.5]}\end{array}$ & $\begin{array}{c}46.4(575 / 1,239) \\
{[43.6-49.2]}\end{array}$ & $\begin{array}{c}89.9(2,102 / 2,337) \\
{[88.7-91.1]}\end{array}$ & $\begin{array}{c}74.9(2,677 / 3,576) \\
{[73.4-76.3]}\end{array}$ \\
\hline AACE/ACE/AME & $\begin{array}{c}73.8(598 / 810) \\
{[70.7-76.7]}\end{array}$ & $\begin{array}{c}75.1(2,077 / 2,766) \\
{[73.4-76.7]}\end{array}$ & $\begin{array}{c}46.5(598 / 1,287) \\
{[43.8-49.2]}\end{array}$ & $\begin{array}{c}90.7(2,077 / 2,289) \\
{[89.5-91.9]}\end{array}$ & $\begin{array}{c}74.8(2,675 / 3,576) \\
{[73.4-76.2]}\end{array}$ \\
\hline EU-TIRADS & $\begin{array}{c}79.0(640 / 810) \\
{[76.1-81.7]}\end{array}$ & $\begin{array}{c}63.7(1,762 / 2,766) \\
{[61.9-65.5]}\end{array}$ & $\begin{array}{c}38.9(640 / 1,644) \\
{[36.6-41.3]}\end{array}$ & $\begin{array}{c}91.2(1,762 / 1,932) \\
{[89.9-92.4]}\end{array}$ & $\begin{array}{c}67.2(2,402 / 3,576) \\
{[65.5-68.7]}\end{array}$ \\
\hline Modified K-TIRADS ${ }_{1.0 \mathrm{~cm}}$ & $\begin{array}{c}88.4(716 / 810) \\
{[86.0-90.4]}\end{array}$ & $\begin{array}{c}59.7(1,652 / 2,766) \\
{[57.9-61.5]}\end{array}$ & $\begin{array}{c}39.1(716 / 1,830) \\
{[36.9-41.4]}\end{array}$ & $\begin{array}{c}94.6(1,652 / 1,746) \\
{[93.5-95.6]}\end{array}$ & $\begin{array}{c}66.2(2,368 / 3,576) \\
{[64.7-67.8]}\end{array}$ \\
\hline Modified K-TIRADS ${ }_{1.5 \mathrm{~cm}}$ & $\begin{array}{c}68.0(551 / 810) \\
{[64.7-71.1]} \\
\end{array}$ & $\begin{array}{c}77.2(2,135 / 2,766) \\
{[75.6-78.7]}\end{array}$ & $\begin{array}{c}46.6(551 / 1,182) \\
{[43.8-49.5]}\end{array}$ & $\begin{array}{c}89.2(2,135 / 2,394) \\
{[87.9-90.4]}\end{array}$ & $\begin{array}{c}75.1(2,686 / 3,576) \\
{[73.7-76.5]}\end{array}$ \\
\hline
\end{tabular}

Values in parentheses are the raw data used to calculate the percentages, and values in brackets are $95 \%$ confidence intervals.

ACR, American College of Radiology; TIRADS, Thyroid Imaging Reporting and Data System; AAACE/ACE/AME, American Association of Clinical Endocrinologists/American College of Endocrinology/Associazione Medici Endocrinologi; EU, European; K-TIRADS, Korean Thyroid Imaging Reporting and Data System.

modified K-TIRADS $1.5 \mathrm{~cm}$ had significantly lower unnecessary FNAB rates than all the other RSS (all $\mathrm{P}<0.05)$.

\section{Discussion}

Our study demonstrated the clinical utility of the modified K-TIRADS. The modified K-TIRADS ${ }_{1.5 \mathrm{~cm}}$ significantly reduced the unnecessary FNAB rates compared to the AACE/ACE/AME and EU-TIRADS in all nodules, while maintaining high sensitivity for detecting malignancy in $>2.0 \mathrm{~cm}$ nodules (up to $98.0 \%$ ). Compared to the ACR-TIRADS, it had a significantly lower unnecessary FNAB rate for small nodules $(\leq 2.0 \mathrm{~cm})$, but higher diagnostic sensitivity for detecting malignancy in nodules $>2.0 \mathrm{~cm}$. Although the modified K-TIRADS $1.0 \mathrm{~cm}$ increased the diagnostic sensitivity for detecting small malignancies, it should be used only after careful consideration of the risks and benefits to the individual patient.

US-based RSS has an essential role in predicting the malignancy risk of thyroid nodules and the decision to perform $\operatorname{FNAB}[1,2]$. However, the sensitivity and specificity of US-based RSS for detecting thyroid cancers remain controversial. As most patients with low-risk small thyroid cancers have an excellent prognosis and low likelihood of mortality, it is also important to reduce overdiagnosis and the harm caused by overtreatment [22]. US-based RSS is expected to reduce the unnecessary FNAB rate while also maintaining appropriate sensitivity for detecting thyroid cancer. Many studies have suggested that increasing sensitivity should be the focus, 
Table 3. Unnecessary FNA rates for the diagnosis of thyroid cancer according to the various guidelines

\begin{tabular}{|c|c|c|c|c|c|}
\hline Guideline & $\begin{array}{c}\text { No. of nodules } \\
\text { indicated for FNAB }\end{array}$ & $\begin{array}{l}\text { No. of malignant nodules } \\
\text { among all FNAB nodules }\end{array}$ & $\begin{array}{c}\text { No. of benign nodules } \\
\text { among all FNAB nodules }(A)\end{array}$ & $\begin{array}{l}\text { Unnecessary FNAB } \\
\text { rate (A/all nodules) }\end{array}$ & $\begin{array}{c}\text { Unnecessary FNAB rate } \\
\text { (A/benign nodules) }\end{array}$ \\
\hline \multicolumn{6}{|l|}{ All nodules $(n=5,708)$} \\
\hline ACR-TIRADS & 2,601 & $845(32.5)$ & $1,756(67.5)$ & $30.8[29.6-32.0]$ & $38.2[36.8-39.6]$ \\
\hline AACE/ACE/AME & 3,262 & $894(27.4)$ & $2,368(72.6)$ & $41.5[40.2-42.8]$ & $51.5[50.1-53.0]$ \\
\hline EU-TIRADS & 3,730 & $940(25.2)$ & $2,790(74.8)$ & $48.9[47.6-50.2]$ & $60.7[59.3-62.1]$ \\
\hline Modified K-TIRADS ${ }_{1.0 \mathrm{~cm}}$ & 3,784 & $1,011(26.7)$ & $2,773(73.3)$ & $48.6[47.3-49.9]$ & $60.3[58.9-61.7]$ \\
\hline Modified K-TIRADS $_{1.5 \mathrm{~cm}}$ & 3,136 & $846(27.0)$ & $2,290(73.0)$ & $40.1[38.9-41.4]$ & $49.8[48.4-51.3]$ \\
\hline \multicolumn{6}{|c|}{ Nodules $>2.0 \mathrm{~cm}(n=2,132)$} \\
\hline ACR-TIRADS & 1,362 & $270(19.8)$ & $1,092(80.2)$ & $51.2[49.1-53.3]$ & $59.6[57.4-61.9]$ \\
\hline AACE/ACE/AME & 1,975 & $296(15.0)$ & $1,679(85.0)$ & $78.8[77.0-80.4]$ & $91.7[90.3-92.9]$ \\
\hline EU-TIRADS & 2,086 & $300(14.4)$ & $1,786(85.6)$ & $83.8[82.1-85.3]$ & $97.5[96.7-98.2]$ \\
\hline Modified K-TIRADS $_{1.0 \mathrm{~cm}}$ & 1,954 & $295(15.1)$ & $1,659(84.9)$ & $77.8[76.0-79.5]$ & $90.6[89.2-91.9]$ \\
\hline Modified K-TIRADS ${ }_{1.5 \mathrm{~cm}}$ & 1,954 & $295(15.1)$ & $1,659(84.9)$ & $77.8[76.0-79.5]$ & $90.6[89.2-91.9]$ \\
\hline \multicolumn{6}{|c|}{ Nodules $\leq 2.0 \mathrm{~cm}(\mathrm{n}=3,576)$} \\
\hline ACR-TIRADS & 1,239 & $575(46.4)$ & $664(53.6)$ & $18.6[17.3-19.9]$ & $24.0[22.5-25.6]$ \\
\hline AACE/ACE/AME & 1,287 & $598(46.5)$ & $689(53.5)$ & $19.3[18.0-20.6]$ & $24.9[23.3-26.6]$ \\
\hline EU-TIRADS & 1,644 & $640(38.9)$ & $1,004(61.1)$ & $28.1[26.6-29.6]$ & $36.3[34.5-38.1]$ \\
\hline Modified K-TIRADS $_{1.0 \mathrm{~cm}}$ & 1,830 & $716(39.1)$ & $1,114(60.9)$ & $31.2[29.7-32.7]$ & $40.3[38.5-42.1]$ \\
\hline Modified K-TIRADS $_{1.5 \mathrm{~cm}}$ & 1,182 & $551(46.6)$ & $631(53.4)$ & $17.6[16.4-18.9]$ & $22.8[21.3-24.4]$ \\
\hline
\end{tabular}

Values are presented as number (\%) and values in brackets are $95 \%$ confidence intervals.

FNA, fine-needle aspiration; FNAB, fine-needle aspiration biopsy; ACR, American College of Radiology; TIRADS, Thyroid Imaging Reporting and Data System; AAACE/ACE/AME, American Association of Clinical Endocrinologists/American College of Endocrinology/Associazione Medici Endocrinologi; EU, European; K-TIRADS, Korean Thyroid Imaging Reporting and Data System.

regardless of the rate of unnecessary FNAB of large nodules ( $>2$ $\mathrm{cm})$, considering the higher risk of aggressive behavior in large cancers. On the other hand, reducing unnecessary FNAB for small nodules $(1-2 \mathrm{~cm})$ is important, given the slow growth rate of small cancers [9]. In simulation studies, when the biopsy size threshold for K-TIRADS 3 increased from 1.5 to $2 \mathrm{~cm}$, there was a decrease $(14.1 \%-16.2 \%)$ in the unnecessary FNAB rate of benign nodules, and a minimal decrease $(1 \%-1.9 \%)$ in the sensitivity $(91.6 \%-$ $94.7 \%)$ for thyroid cancer, compared to the original K-TIRADS (sensitivity, 93.5\%-95.7\%) $[8,15]$. When the biopsy size threshold was increased from 1.0 to $1.5 \mathrm{~cm}$ for K-TIRADS 4, there was a substantial decrease $(27 \%-28.9 \%)$ in the unnecessary FNAB rate of benign nodules and a further significant decrease $(15 \%-27.1 \%)$ in the sensitivity $(66.4 \%-80.7 \%)$ for thyroid cancer $[8,15]$. Based on these results, it was planned to modify the K-TIRADS biopsy size threshold to $2.0 \mathrm{~cm}$ for K-TIRADS 3 and 1.0 or $1.5 \mathrm{~cm}$ for K-TIRADS 4 in this study.

The modified K-TIRADS $1.5 \mathrm{~cm}$ reduced the unnecessary FNAB rate to $17.6 \%$ in small nodules $(\leq 2.0 \mathrm{~cm})$. This was significantly lower than the rate for the AACE/ACE/AME, EU-TIRADS, and ACR-TIRADS $(18.6 \%-28.1 \%)$. Moreover, it maintained high sensitivity (up to
$98.0 \%)$ for detecting large cancers $(>2.0 \mathrm{~cm})$. Compared to the ACR-TIRADS, the modified K-TIRADS ${ }_{1.5 \mathrm{~cm}}$ had a higher unnecessary FNAB rate $(40.1 \%$ and $30.8 \%$, respectively) for all nodules, a lower unnecessary FNAB rate $(17.6 \%$ and $18.6 \%$, respectively) for small nodules $(\leq 2.0 \mathrm{~cm})$, and significantly higher sensitivity for detecting large cancers $(98.0 \%$ and $89.7 \%$, respectively). The modified K-TIRADS ${ }_{1.0 \mathrm{~cm}}$ had a diagnostic sensitivity up to $88.4 \%$ for small cancers, but the unnecessary FNAB rate was significantly higher compared to the ACR-TIRADS and AACD/ACE/AME guidelines. Therefore, it is suggested that the modified K-TIRADS ${ }_{1.0 \mathrm{~cm}}$ be applied only after careful consideration of clinical factors, family history, and US features.

This study had several limitations. First, it only included thyroid nodules that had undergone US-guided FNAB, which is usually performed in thyroid nodules with suspicious US features, or in the largest nodule if no suspicious US features are detected; this may have led to selection bias. Second, the final diagnoses of benign nodules were based on the cytopathological results and surgical histological findings, which may have resulted in false-negative or false-positive results. Third, this study included a large proportion of papillary thyroid carcinomas. If the proportion of follicular cancers 
increase, the diagnostic performance may be changed.

In conclusion, the modified K-TIRADS ${ }_{1.5 \mathrm{~cm}}$ reduced the unnecessary FNAB rates in all nodules compared to the AACE/ACE/AME and EU-TIRADS, while maintaining high sensitivity for detecting malignancies $>2.0 \mathrm{~cm}$. In particular, it showed higher sensitivity for detecting malignancies $>2.0 \mathrm{~cm}$, but a lower unnecessary FNAB rate for small nodules $(1.0-2.0 \mathrm{~cm})$ than the ACR-TIRADS.

ORCID: Eun Ju Ha: https://orcid.org/0000-0002-1234-2919; Jung Hee Shin: https:// orcid.org/0000-0001-6435-7357; Dong Gyu Na: https://orcid.org/0000-0001-64221652; So Lyung Jung: https://orcid.org/0000-0002-3267-8399; Young Hen Lee: https://orcid.org/0000-0001-7739-4173; Wooyul Paik: https://orcid.org/0000-00019617-6227; Min Ji Hong: https://orcid.org/0000-0001-7818-4346; Yeo Koon Kim: https://orcid.org/0000-0002-8729-9484; Chang Yoon Lee: https://orcid.org/00000001-8645-3569

\section{${ }^{*}$ Author affiliations}

'Department of Radiology, Ajou University School of Medicine, Suwon; ${ }^{2}$ Department of Radiology and Center for Imaging Science, Samsung Medical Center, Sungkyunkwan University School of Medicine, Seoul; ${ }^{3}$ Department of Radiology, GangNeung Asan Hospital, University of Ulsan College of Medicine, Gangneung; ${ }^{4}$ Department of Radiology, Yeouido St. Mary's Hospital, College of Medicine, The Catholic University of Korea, Seoul; ${ }^{5}$ Department of Radiology, Korea University Ansan Hospital, Korea University College of Medicine, Ansan; ${ }^{6}$ Department of Radiology, ChungAng University Hospital, Chung-Ang University College of Medicine, Seoul; ${ }^{7}$ Department of Radiology, Seoul National University Bundang Hospital, Seoul National University College of Medicine, Seongnam; ${ }^{8}$ Department of Radiology, Research Institute and Hospital, National Cancer Center, Goyang, Korea

\section{Author Contributions}

Conceptualization: Ha EJ, Shin JH, Na DG, Jung SL, Paik W. Data acquisition: Ha EJ, Shin JH, Na DG, Jung SL, Lee YH, Paik W, Hong MJ, Kim YK, Lee CY. Data analysis or interpretation: Ha EJ, Na DG. Drafting of the manuscript: Ha EJ. Critical revision of the manuscript: Shin JH, Na DG, Jung SL, Lee YH, Paik W, Hong MJ, Kim YK, Lee CY. Approval of the final version of the manuscript: all authors.

\section{Conflict of Interest}

No potential conflict of interest relevant to this article was reported.

\section{Acknowledgments}

This study was supported by a Research Fund of the Korean Society of Ultrasound in Medicine for 2021, by the Medical Research Promotion Program through the GangNeung Asan Hospital funded by the Asan Foundation (2018-C03), and by a research fund from the Korean Society of Radiology through Radiology Imaging Network of Korea for Clinical Research (RINK-CR). We thank Dr. Ji Eun Shin (Department of Radiology, CHA Gangnam Medical Center, College of Medicine, Cha University), Dr. Younghee Yim (Department of Radiology, Chung-Ang University Hospital, ChungAng University College of Medicine), Dr. Nami Choi (Department of Radiology, Konkuk University Medical Center, Konkuk University Scool of Medicine), Dr. Hwa Seon Shin (Department of Radiology, Gyeongsang National University Hospital), Dr. Sung-Hye You (Department of Radiology, Korea University Anam Hospital, Korea University Hospital), Dr. Beomsu Kim (Department of Radiology, Kosin University Gaspel Hospital), Dr. Jin Yong Sung (Department of Radiology, Thyroid Center, Daerim St. Mary's Hospital), Dr. Hyun Jeong Kim (Department of Radiology, Daejeon St. Mary's Hospital, College of Medicine, The Catholic University of Korea), Dr. Dae Bong Kim (Department of Radiology, Dongguk University Ilsan Hospital), Dr. Ji-hoon Kim (Department of Radiology, Seoul National University Hospital, Seoul National University College of Medicine), Dr. SunWon Park (Department of Radiology, Seoul National University Hospital, Seoul National University College of Medicine; Department of Radiology, Seoul Metropolitan Government Seoul National University Boramae Medical Center), Dr. Ji Ye Lee (Department of Radiology, Seoul National University Hospital, Seoul National University College of Medicine), Dr. Hyun Kyung Lim (Department of Radiology, Soonchunhyang University Seoul Hospital), Dr. Ra Gyoung Yoon (Department of Radiology, Nowon Eulji Medical Center, Eulji University), Dr. Yoo Jin Lee (Department of Radiology, Busan Paik Hospital, Inje University College of Medicine), Dr. Joon Hyung Lee (Department of Radiology, Inje University Haeundae Paik Hospital), Dr. Hye Shin Ahn (Department of Radiology, Chung-Ang University Hospital, Chung-Ang University College of Medicine), Dr. Tae Yoon Kim (Department of Radiology, Hanyang University Guri Hospital, Hanyang University College of Medicine), Dr. JeeYoung Kim (Department of Radiology, Eunpyeong St. Mary's Hospital), Dr. Jung Hwan Baek (Department of Radiology and Research Institute of Radiology, Asan Medical Center, University of Ulsan College of Medicine), Dr. Young Jun Choi (Department of Radiology and Research Institute of Radiology, Asan Medical Center, University of Ulsan College of Medicine), and Dr. Sae Rom Chung (Department of Radiology and Research Institute of Radiology, Asan Medical Center, University of Ulsan College of Medicine) for their participation in data collection.

\section{Supplementary Material}

Supplementary Table 1. Summary of US features and US-guided FNAB recommendations (https://doi.org/10.14366/usg.21056). 


\section{References}

1. Shin JH, Baek JH, Chung J, Ha EJ, Kim JH, Lee YH, et al. Ultrasonography diagnosis and imaging-based management of thyroid nodules: revised Korean Society of Thyroid Radiology consensus statement and recommendations. Korean J Radiol 2016;17:370-395.

2. Haugen BR, Alexander EK, Bible KC, Doherty GM, Mandel SJ, Nikiforov YE, et al. 2015 American Thyroid Association management guidelines for adult patients with thyroid nodules and differentiated thyroid cancer: the American Thyroid Association Guidelines Task Force on Thyroid Nodules and Differentiated Thyroid Cancer. Thyroid 2016;26:1-133.

3. Gharib H, Papini E, Garber JR, Duick DS, Harrell RM, Hegedus L, et al. American Association of Clinical Endocrinologists, American College of Endocrinology, and Associazione Medici Endocrinologi medical guidelines for clinical practice for the diagnosis and management of thyroid nodules: 2016 update. Endocr Pract 2016;22:622-639.

4. Russ G, Bonnema SJ, Erdogan MF, Durante C, Ngu R, Leenhardt L. European Thyroid Association guidelines for ultrasound malignancy risk stratification of thyroid nodules in adults: the EU-TIRADS. Eur Thyroid J 2017;6:225-237.

5. Tessler FN, Middleton WD, Grant EG, Hoang JK, Berland LL, Teefey SA, et al. ACR Thyroid Imaging, Reporting and Data System (TIRADS): White Paper of the ACR TI-RADS Committee. J Am Coll Radiol 2017; 14:587-595.

6. Ha EJ, Na DG, Baek JH, Sung JY, Kim JH, Kang SY. US Fine-needle aspiration biopsy for thyroid malignancy: diagnostic performance of seven society guidelines applied to 2000 thyroid nodules. Radiology 2018;287:893-900.

7. Ha EJ, Na DG, Moon WJ, Lee YH, Choi N. Diagnostic performance of ultrasound-based risk-stratification systems for thyroid nodules: comparison of the 2015 American Thyroid Association Guidelines with the 2016 Korean Thyroid Association/Korean Society of Thyroid Radiology and 2017 American College of Radiology guidelines. Thyroid 2018;28:1532-1537.

8. Ha SM, Baek JH, Na DG, Suh CH, Chung SR, Choi YJ, et al. Diagnostic performance of practice guidelines for thyroid nodules: thyroid nodule size versus biopsy rates. Radiology 2019;291:92-99.

9. Na DG, Paik W, Cha J, Gwon HY, Kim SY, Yoo RE. Diagnostic performance of the modified Korean Thyroid Imaging Reporting and Data System for thyroid malignancy according to nodule size: a comparison with five society guidelines. Ultrasonography 2021;40:474-485.

10. Kim DH, Chung SR, Choi SH, Kim KW. Accuracy of thyroid imaging reporting and data system category 4 or 5 for diagnosing malignancy: a systematic review and meta-analysis. Eur Radiol 2020;30:5611-5624.

11. Kim PH, Suh CH, Baek JH, Chung SR, Choi YJ, Lee JH. Diagnostic performance of four ultrasound risk stratification systems: a systematic review and meta-analysis. Thyroid 2020;30:1159-1168.

12. Yim Y, Na DG, Ha EJ, Baek JH, Sung JY, Kim JH, et al. Concordance of three international guidelines for thyroid nodules classified by ultrasonography and diagnostic performance of biopsy criteria. Korean J Radiol 2020;21:108-116.

13. Middleton WD, Teefey SA, Reading CC, Langer JE, Beland MD, Szabunio MM, et al. Comparison of performance characteristics of American College of Radiology TI-RADS, Korean Society of Thyroid Radiology TIRADS, and American Thyroid Association guidelines. AJR Am J Roentgenol 2018;210:1148-1154.

14. Grani G, Lamartina L, Ascoli V, Bosco D, Biffoni M, Giacomelli L, et al. Reducing the number of unnecessary thyroid biopsies while improving diagnostic accuracy: toward the "Right" TIRADS. J Clin Endocrinol Metab 2019;104:95-102.

15. Yoon SJ, Na DG, Gwon HY, Paik W, Kim WJ, Song JS, et al. Similarities and differences between Thyroid Imaging Reporting and Data Systems. AJR Am J Roentgenol 2019;213:W76-W84.

16. Cibas ES, Ali SZ. The 2017 Bethesda System for Reporting Thyroid Cytopathology. Thyroid 2017;27:1341-1346.

17. Jung CK, Baek JH, Na DG, Oh YL, Yi KH, Kang HC. 2019 Practice guidelines for thyroid core needle biopsy: a report of the Clinical Practice Guidelines Development Committee of the Korean Thyroid Association. J Pathol TransI Med 2020;54:64-86.

18. Na DG, Baek JH, Jung SL, Kim JH, Sung JY, Kim KS, et al. Core needle biopsy of the thyroid: 2016 consensus statement and recommendations from Korean Society of Thyroid Radiology. Korean J Radiol 2017;18:217-237.

19. Gwon HY, Na DG, Noh BJ, Paik W, Yoon SJ, Choi SJ, et al. Thyroid nodules with isolated macrocalcifications: malignancy risk of isolated macrocalcifications and postoperative risk stratification of malignant tumors manifesting as isolated macrocalcifications. Korean J Radiol 2020;21:605-613.

20. Na DG, Kim DS, Kim SJ, Ryoo JW, Jung SL. Thyroid nodules with isolated macrocalcification: malignancy risk and diagnostic efficacy of fine-needle aspiration and core needle biopsy. Ultrasonography 2016;35:212-219.

21. Paik W, Na DG, Gwon HY, Kim J. CT features of thyroid nodules with isolated macrocalcifications detected by ultrasonography. Ultrasonography 2020;39:130-136.

22. Ito $Y$, Miyauchi A, Oda H. Low-risk papillary microcarcinoma of the thyroid: a review of active surveillance trials. Eur J Surg Oncol 2018;44:307-315. 